DOI: http://dx.doi.org/10.1590/fst.2014.0055

\title{
Extraction optimization of antioxidant polysaccharides from leaves of Gynura bicolor (Roxb. \& Willd.) DC
}

Fen YAN ${ }^{1}$, Xuena YANG ${ }^{1}$, Chang LIU ${ }^{1}$, Shangrong HUANG ${ }^{1}$, Lan LIAO${ }^{1}$, Caili FU ${ }^{1 *}$

\begin{abstract}
Orthogonal design was employed to study the effect of extraction time, temperature and liquid-to-solid ratio on the production of antioxidant polysaccharides from leaves of Gynura bicolor (PLG). Analysis of variance was performed on the data obtained. The most relevant variable was extraction time. A liquid-solid ratio of $30: 1(\mathrm{v} / \mathrm{w})$, a temperature of $80^{\circ} \mathrm{C}$ and an extraction time of $3 \mathrm{~h}$ were found to be optimal for PLG. The optimal extraction yield of $4.9 \%$ was obtained through additional verification test. Hydroxyl radical-scavenging activity, reducing power and ferrous ion chelating ability of PLG were determined. PLG possess concentration-dependent antioxidant potency and $\mathrm{IC}_{50}$ of PLG was $4.67,0.24$ and $4.31 \mathrm{mg} / \mathrm{mL}$ for hydroxyl radical-scavenging and ferric ion chelating abilities as well as reducing power, respectively. The results suggest that G. bicolor polysaccharides could be potential source of natural antioxidant and be contributor to the health benefits of G. bicolor.
\end{abstract}

Keywords: Gynura bicolor; polysaccharide; orthogonal design; antioxidant activity.

\section{Introduction}

Gynura bicolor (Roxb. \& Willd.) DC., an edible plant with a good flavor, is widely consumed as a traditional vegetable in Asian countries. G. bicolor was also used for treating diabetes mellitus in folk medicine and pioneers investigated some bioactive components in this plant with modern techniques. It was reported that water-extracts of G. bicolor could significantly reduce the level of blood glucose in diabetes rats (Wang et al., 2013). Hayashi et al. (2002) reported that hot water extract of $G$. bicolor inhibited proliferation of the HL60 human leukemia cell. In addition, G. bicolor water-extract and sub-fraction scavenged DPPH radical (Hayashi et al., 2002). Shimizu et al. (2000) insolated three antioxidant anthocyanins from water-extracts of the G. bicolor. Excitingly, G. bicolor anthocyanins can be a natural food color with high stability and safety (Shimizu et al., 2000). Besides anthocyanins, polysaccharides were important phytochemcals in the water-extracts from many medical plants. However, research on the polysaccharides from G. bicolor is rare.

Polysaccharides are polymeric biomacromolecules commonly composed of more than 10 monosaccharide units existing in plants, bacteria, algae and animals. Lots of healthbenefit polysaccharides have been isolated successfully from natural sources such as mushroom, Ganoderma lucidum and Cordyceps sinensis. These polysaccharides showed multiple and complex biological activities such as antitumor, anticancer, antioxidant and anti-inflammatory.

Nie et al. (2013) and Wang et al. (2013) isolated polysaccharide with good antioxidant activities such as scavenging hydroxyl, reducing power, and superoxide anion radicals from Cordyceps sinensis and Phellinus nigricans, respectively. In addition, Mamani Chambi \& Ferreira Grosso (2011) also inferred that polysaccharides are ideal materials for preparation of biodegradables functional films.
Hydroxyl radical is the most unstable radicals which can react easily with other substances in the body resulting in damages of adjacent biomolecules such as DNA, nucleic acid and proteins. These damages lead to human diseases such as cancer and aging (Halliwell \& Gutteridge, 1989; Aruoma, 1998). Antioxidant could be used to remove the hydroxyl radicals to make effective defenses of a living body against various diseases. Reducing power assay is widely used to assess the potency of a selected antioxidant. During the reducing power assay, the presence of reductants in the fractions could result in reducing $\mathrm{Fe}^{3+} /$ ferricyanide complex to the ferrous form $\left(\mathrm{Fe}^{2+}\right)$ (Chung et al., 2002). Transition metals, such as $\mathrm{Co}^{2+}, \mathrm{Fe}^{2+}$ and $\mathrm{Pb}^{2+}$, have been indicated that could trigger the process of free radical reaction to damage the cellular (Chen et al., 2012). Thus it is necessary to prevent the case happen by introducing antioxidant to inhibit the activity of free radical. Some reports pointed that metal chelate could reduce the concentration of the catalyzing transition metal in lipid peroxidation, which means it plays an important role in antioxidant mechanisms (Qiao et al., 2009).

The objective of this study was to optimize the production of polysaccharides from leaves of G. bicolor (PLG). The antioxidant abilities of PLG were then analyzed by in vitro systems including reducing power, hydroxyl radical-scavenging and ferrous ion chelating abilities.

\section{Materials and methods}

\subsection{Chemicals}

G. bicolor was purchased from local market (Fuzhou, Fujian province, China). The plant with the reddish purple color on the abaxial side was authenticated by Prof. Hong Fu in 
College of Bioscience \& Biotechnology. A voucher specimen (No. GbLFCL22) is deposited at the College of Bioscience \& Biotechnology, Fuzhou University, China. The sample was ground into fine powder using a grinder after natural drying in the sun at room temperature $\left(22-30^{\circ} \mathrm{C}\right)$ for a day. The materials were stored at room temperature in a desiccator for further research. Ascorbic acid, ferrozine, EDTA, salicylic acid, ferrous chloride, ferric trichloride, potassium ferricyanide, ferrous sulfate and ethanol were purchased from Sigma Chemicals.

\subsection{Extraction and purified of polysaccharides from the leaves of G. bicolor}

Extraction and purified of polysaccharides from the leaves of $G$. bicolor was performed according to a previous method (Nour et al., 2014). Briefly, the dry powdered leaves (10 g) were separately suspended in distilled water at the established volume and then stirred for extraction at the established temperature and time. The mixture was then centrifuged for $20 \mathrm{~min}$ at $5000 \mathrm{rpm}$. The supernatant was concentrated to $1 / 5$ of the original volume by evaporation at $45^{\circ} \mathrm{C}$. Three volumes of absolute ethanol was added into the filtered solution and produced polysaccharide precipitate. The precipitated materials were collected by centrifugation for $20 \mathrm{~min}$ at $5000 \mathrm{rpm}$ and then purified using the classic Sevag method (Sevag et al., 1938).

\subsection{Experimental design}

Design of the experiment can not only reduce the experimental time and costs but economize the work. Effect of liquid-to-solid ratio, extraction time and temperature on polysaccharide production was preliminarily investigated by one-factor-at-a-time tests, which vary one independent parameter with fixing the others in a group of experiments. Then, the optimization process was performed with an orthogonal design, which was widely used for extraction optimization (Chen et al., 2014; Martin et al., 2012). Table 1 presented that the code and levels for each factor which may affect the yield of polysaccharides from the leaves of G. bicolor.

\subsection{Statistical analysis}

All measurements were performed in triplicate. Means were statistically analyzed using analysis of variance (ANOVA). The Duncan's New Multiple-range test were applied to determine the differences among the means. P values $<0.05$ were regarded as being statistically significant.

\subsection{Determination of polysaccharides content}

The determination of polysaccharides content was done by phenol-sulfuric acid method (Masuko et al., 2005). Briefly,
$100 \mu \mathrm{l}$ of crude polysaccharides solution was mixed with $300 \mu \mathrm{l}$ concentrated sulphuric acid to initiated the reaction, following $60 \mu \mathrm{l}$ of $5 \%$ phenol was added and the mixture was kept at $100{ }^{\circ} \mathrm{C}$ for $15 \mathrm{~min}$, after cooling to the room temperature, the absorbance of the reaction mixture was measured at $490 \mathrm{~nm}$ using the spectrophotometer. The total polysaccharides content was calculated with D-glucose as standard.

\subsection{Hydroxyl radical-scavenging activities}

Hydroxyl radical-scavenging activities of polysaccharide from $G$. bicolor were determined according to previous method with slightly modification (Vissotto et al., 2013). $0.5 \mathrm{ml}$ of sample solutions with various concentrations were mixed with $1.5 \mathrm{ml}$ of $2.0 \mathrm{mmol} / \mathrm{L} \mathrm{FeSO}_{4}$, then $1.5 \mathrm{ml}$ of $6.0 \mathrm{mmol} / \mathrm{L} \mathrm{H}_{2} \mathrm{O}_{2}$ and $1.5 \mathrm{ml}$ of $6.0 \mathrm{mmol} / \mathrm{L}$ sodium salicylate were added. The mixture was incubated at $37^{\circ} \mathrm{C}$ water bath for $30 \mathrm{~min}$. The absorbance of the mixture was measured at $510 \mathrm{~nm}$ after cooling to the room temperature. VC was used as the positive control.

\subsection{Reduction power}

The reducing powers of polysaccharides from G. bicolor were determined according to the method described by Gulcin with minor modification (Gulcin et al., 2003). Briefly, $1 \mathrm{ml}$ of sample solutions with various concentrations were mixed with $2.5 \mathrm{ml}$ phosphate buffer $(0.2 \mathrm{M}, \mathrm{pH} 6.6)$ and $2.5 \mathrm{ml}$ potassium ferricyanide $(1 \%)$, the mixture was incubated at $50{ }^{\circ} \mathrm{C}$ for $20 \mathrm{~min}$. Aliquots $(1.0 \mathrm{ml})$ of $10 \%$ trichloroacetic acid was added to the mixture, and centrifuged at $4000 \mathrm{rpm}$ for $10 \mathrm{~min}$. After which, $2.5 \mathrm{ml}$ of the upper layer of solution was mixed with $2.5 \mathrm{ml}$ distilled water and $0.5 \mathrm{ml}$ of $0.1 \%$ ferric chloride. The absorbance of the reaction mixture was measured at $700 \mathrm{~nm}$ using a spectrophotometer. Increased absorbance of the reaction indicates increased reducing power. VC was used as the positive control.

\subsection{Ferrous ion chelating activity}

Ferrous ion chelating activity was estimated by the decrease in the maximal absorbance of the iron-ferrozine complex (Dinis et al., 1994). Briefly, $1 \mathrm{ml}$ of sample solutions with various concentrations were mixed with $100 \mu \mathrm{l}$ of $2.0 \mathrm{mmol} / \mathrm{L}$ $\mathrm{FeCl}_{2} \bullet 4 \mathrm{H}_{2} \mathrm{O}$ solution and $3.7 \mathrm{ml}$ distilled water. The reaction was initiated by the addition of $200 \mu \mathrm{l}$ of $5.0 \mathrm{mmol} / \mathrm{L}$ ferrozine and after the mixture had reached equilibrium (20 $\mathrm{min}$ ), the absorbance of the reaction mixture was measured at $562 \mathrm{~nm}$ using a spectrophotometer. EDTA was used as the positive control.

Table 1. Orthogonal experimental factors and levels.

\begin{tabular}{cccc}
\hline Levels & A: Time $(\mathrm{h})$ & B: liquid-to-solid ratio $(\mathrm{mL} / \mathrm{g})$ & C: \\
\hline 1 & 2.0 & $20: 1$ & 60 \\
2 & 2.5 & $30: 1$ & 70 \\
3 & 3.0 & $40: 1$ & 80 \\
\hline
\end{tabular}




\section{Results and discussion}

\subsection{Effect of liquid-to-solid ratio, time and temperature on polysaccharide production}

It is needful and useful to perform one-factor-at-a-time tests, which vary one independent parameter with fixing the others in a group of experiments, to investigate the parameters towards the yield of polysaccharides. Some reports indicated that liquid-to-solid ratio, extraction time and temperature affected the yield of polysaccharides (Nie et al., 2013; Wang et al., 2014; Chen et al., 2014). To find a suitable time, extraction was performed for 1-4h while keeping extraction temperature at $50{ }^{\circ} \mathrm{C}$ and liquid-to-solid ratio at 20:1.(Figure 1a). As shown in Figure 1a, the extraction yield of polysaccharide from leaves of G. bicolor quickly increased from 1 to $2.5 \mathrm{~h}$ and the highest extraction yield was obtained at $2.5 \mathrm{~h}$. The yield was leveled off in spite of further increasing extract time. Similarly, Figure $1 \mathrm{~b}$ shows the effect of different between 10:1 and 50:1 (ml/g) on the extraction of polysaccharide and the extraction yield showed an obvious increase as the ratio increased form 10:1 to 30:1. Figure 1c shows a sharp increase in extraction efficiency as the temperature was increased from 40 to $70{ }^{\circ} \mathrm{C}$ and then leveled off with further increased. To save energy, temperature being lower than $70^{\circ} \mathrm{C}$ was suitable.

\subsection{Orthogonal experimental design for polysaccharide extraction}

In order to study the relevance of variables and optimize the best condition for the extraction of polysaccharide from leaves of G. bicolor (PLG), an orthogonal experiment design was used to explore the best combination of liquid-to-solid ratio, extraction time and temperature (Table 1). PLG yield and magnitude order of R (the index of Max Dif) were recorded in Table 2. According to the results of the orthogonal experimental test, the order effects of all factors on extraction yield of PLG was A (extraction time) $>\mathrm{C}$ (temperature) $>\mathrm{B}$ (liquid-to-solid ratio). The optimum level of each factor can be determined according to the magnitude order of R (Bai et al., 2012), thus the optimum
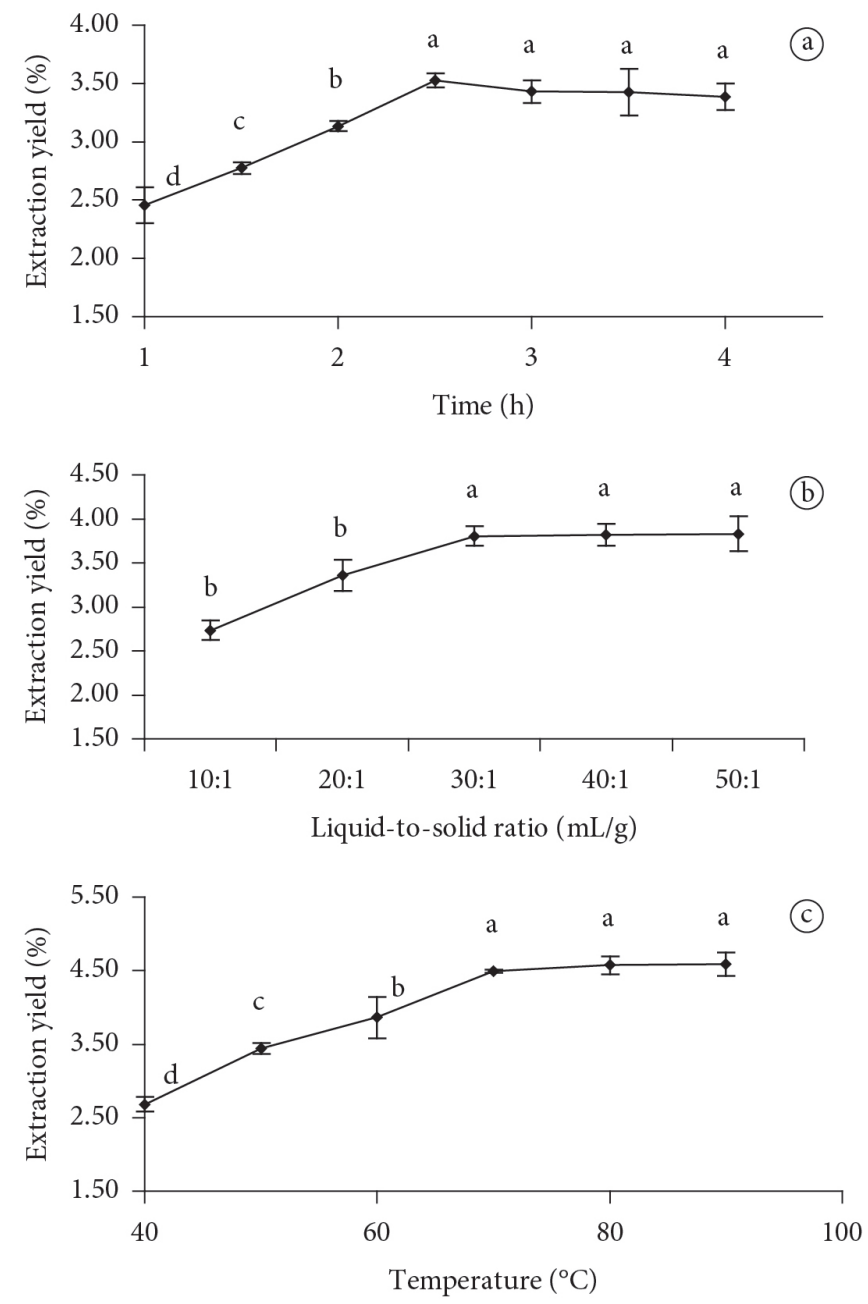

Figure 1. Effect of extraction time (a), liquid-to-solid ratio (b) and temperatue (c) on yield of polysaccharides extracted from leaves of G. bicolor.

Table 2. Orthogonal array and yield of polysaccharides from leaves of G. bicolor.

\begin{tabular}{|c|c|c|c|c|c|}
\hline No. & $\begin{array}{c}\text { A } \\
\text { Time (h) }\end{array}$ & $\begin{array}{c}\text { B } \\
\text { liquid-to-solid ratio }\end{array}$ & $\begin{array}{c}\mathrm{C} \\
\text { Temperature }\left({ }^{\circ} \mathrm{C}\right)\end{array}$ & Control & Yield (\%) \\
\hline 1 & $1(2.0)$ & $1(20: 1)$ & $1(60)$ & 1 & 3.37 \\
\hline 2 & 1 & $2(30: 1)$ & $2(70)$ & 2 & 3.56 \\
\hline 3 & 1 & $3(40: 1)$ & $3(80)$ & 3 & 4.05 \\
\hline 4 & $2(2.5)$ & 1 & 2 & 3 & 3.92 \\
\hline 5 & 2 & 2 & 3 & 1 & 4.58 \\
\hline 6 & 2 & 3 & 1 & 2 & 3.54 \\
\hline 7 & $3(3.0)$ & 1 & 3 & 2 & 4.52 \\
\hline 8 & 3 & 2 & 1 & 3 & 4.25 \\
\hline 9 & 3 & 3 & 2 & 1 & 4.60 \\
\hline $\mathrm{K}_{1}$ & 21.96 & 23.59 & 22.31 & 25.18 & \\
\hline $\mathrm{K}_{2}$ & 24.05 & 24.78 & 24.25 & 23.22 & \\
\hline $\mathrm{K}_{3}$ & 26.84 & 24.48 & 26.29 & 24.44 & \\
\hline $\mathrm{R}^{3}$ & 4.89 & 1.19 & 3.98 & 1.96 & \\
\hline
\end{tabular}


conditions would be extraction time of $3 \mathrm{~h}$, liquid-to-solid ratio of $30: 1(\mathrm{~mL} / \mathrm{g})$ and temperature of $80^{\circ} \mathrm{C}$.

Significance was investigated by Fisher's test and the corresponding ANOVA for PLG production is shown in Table 3. Agreed with Max Dif analysis, the most relevant variable was extraction time followed by extraction temperature. The results pointed out that it is important to keep enough extraction time. To certify experimental reproducibility and realities for optimal combination, three additional verification tests under above optimal conditions were carried out. The maximum extraction yield of $4.9 \%$ based dry weight was obtained and this yield is higher than that of any experiment in Table 2, which implied that a liquid-to-solid ratio of $30: 1(\mathrm{v} / \mathrm{w})$, a temperature of $80^{\circ} \mathrm{C}$ and an extraction time of $3 \mathrm{~h}$ were really the most suitable conditions for PLG production.

\subsection{Antioxidant activities of polysaccharide from leaves of G. bicolor}

\section{Hydroxyl radical-scavenging activities}

In our study, dose-response curves of hydroxyl radical scavenging activities of the polysaccharide from leaves of G. bicolor (PLG) was shown in Figure 2. The scavenging effect of PLG towards the hydroxyl radical was $90 \%$ at the concentration of $10 \mathrm{mg} / \mathrm{mL}$. The $\mathrm{IC}_{50}$ of polysaccharide from $G$. bicolor and VC was $4.67 \mathrm{mg} / \mathrm{mL}$ and $1.20 \mathrm{mg} / \mathrm{mL}$, respectively. These results indicate that PLG should be explored as a promising antioxidant. Similarly, Jia et al. (2014) also verified that the hydroxyl scavenging activity increased with increasing concentration of Hawk tea polysaccharides. The $\mathrm{EC}_{50}$ values of three polysaccharides products from the $P$. cocos were reported as 1.457, 2.109 and $1.754 \mathrm{mg} / \mathrm{mL}$, respectively (Tang et al., 2014).

\section{Reducing power}

Figure 3 presented the dose-response curves for reducing power of the polysaccharide from G. bicolor. VC was a positive control, the $\mathrm{IC}_{50}$ of polysaccharide from G. bicolor and VC was $4.31 \mathrm{mg} / \mathrm{mL}$ and $0.05 \mathrm{mg} / \mathrm{mL}$, respectively. Reducing power is not the main antioxidant point of PLG. Similar results have been deduced by Kozarski et al. (2012) who evaluated the antioxidant activities of polysaccharide from G. lucidum. Kozarski et al. (2012) proved the reducing power of the polysaccharide from G. lucidum increased as the concentration increased from 0.1 to $5.0 \mathrm{mg} / \mathrm{mL}$ and reached a highest level of 3.2 at $5.0 \mathrm{mg} / \mathrm{mL}$.

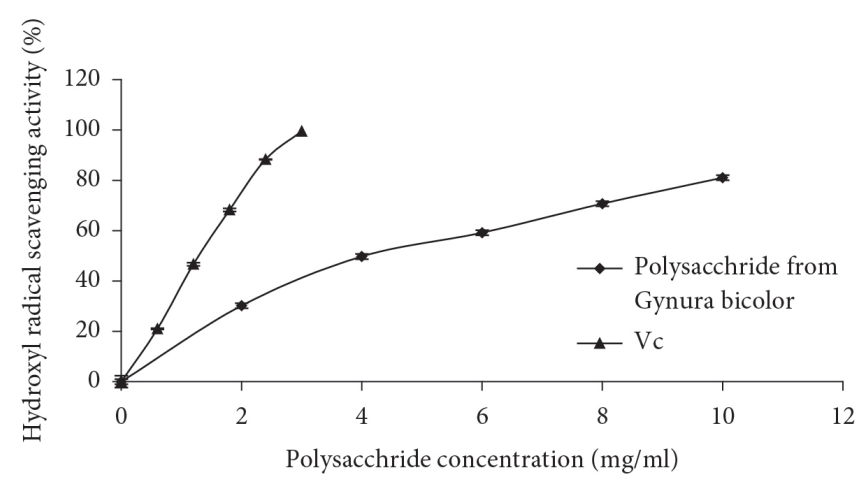

Figure 2. Hydroxyl radical scavenging activities of G. bicolor polysaccharides and VC.
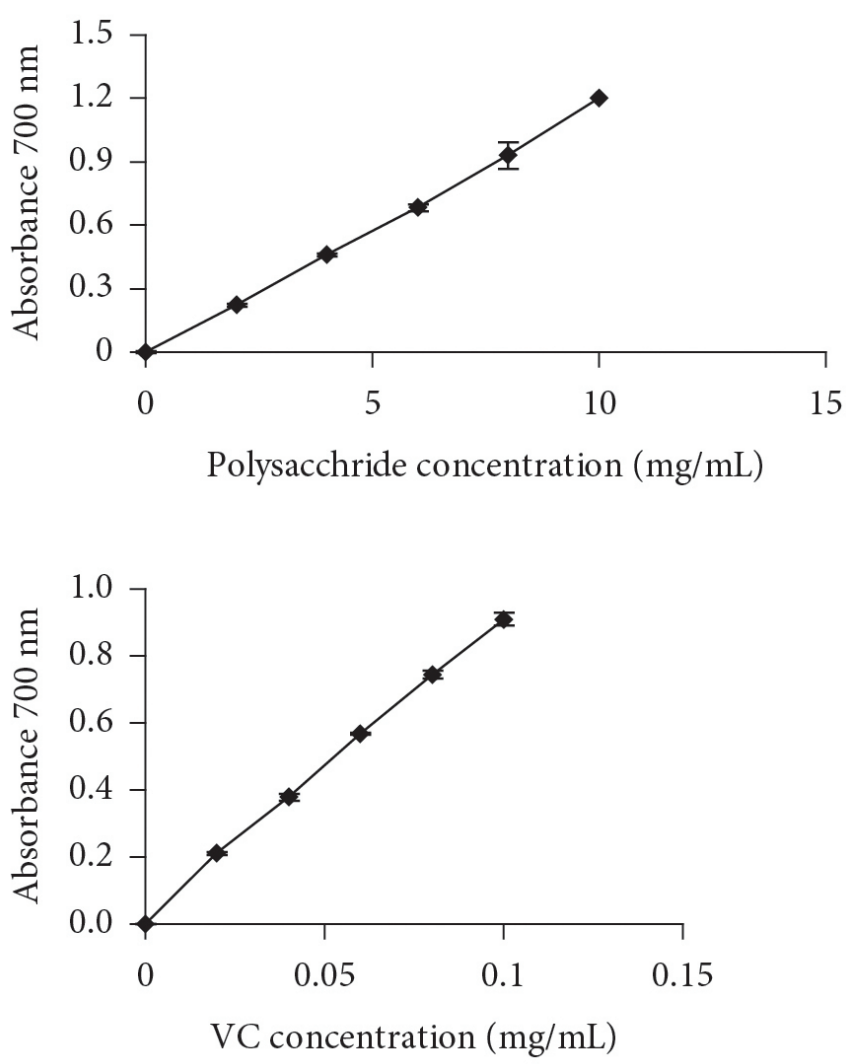

Figure 3. Reducing power of activities of G. bicolor polysaccharides and VC.

Table 3. ANOVA value obtained from orthogonal experiment design for extraction optimization of polysaccharides from leaves of G. bicolor.

\begin{tabular}{cccc}
\hline Model term & Sum of squares & $d f$ & Mean square \\
\hline A & 1.9996 & 2 & 0.9998 \\
B & 0.1277 & 2 & 0.0638 \\
C & 1.3179 & 2 & 0.6589 \\
$\mathrm{e}$ & 0.4534 & 11 & 0.0412 \\
$\mathrm{e}^{\Delta}$ & 0.5811 & 13 & 0.0446 \\
sum & 4.4798 & 30 & \\
\hline
\end{tabular}

$\mathrm{F}_{0.05}(2,11)=7.21, \mathrm{~F}_{0.01}(2,11)=3.98$. 


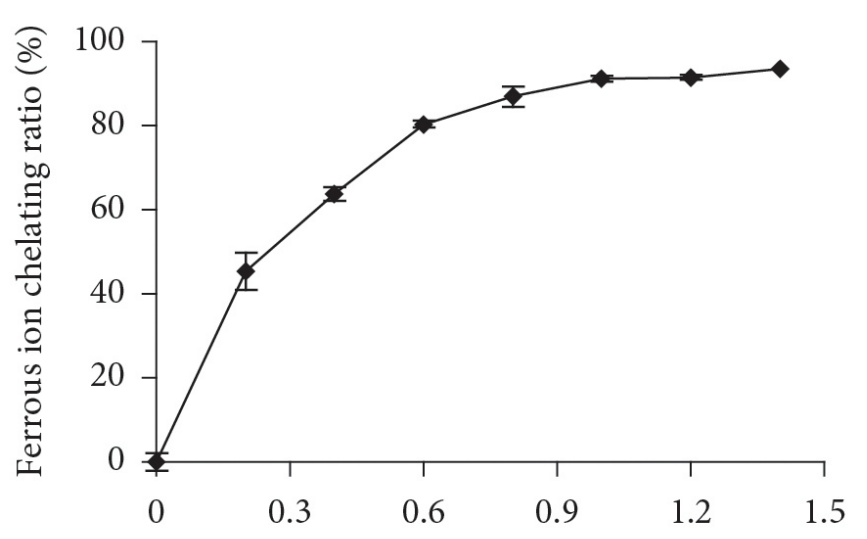

Polysacchride concentration $(\mathrm{mg} / \mathrm{mL})$

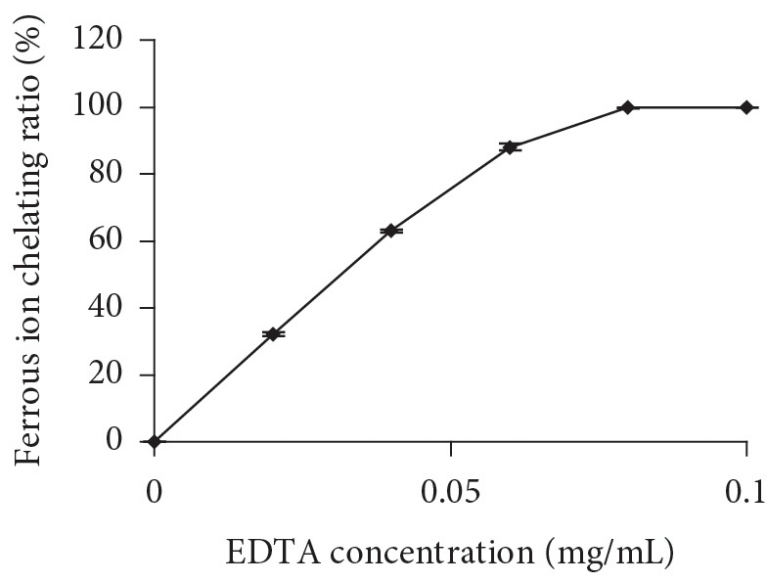

Figure 4. Ferrous ion chelating chelating activities of G. bicolor polysaccharides and EDTA.

\section{Ferrous ion chelating activity}

In our study, we purified the polysaccharide which was extracted from G. bicolor and analyzed the ferrous ion chelating activity. As shown in Figure 4, the ferrous ion chelating activity increased as the concentration of the extract increased. The effect on the chelating activity was above $90 \%$ at the concentration of $1.0 \mathrm{mg} / \mathrm{mL}$. EDTA was a positive control, the $\mathrm{IC}_{50}$ of polysaccharide from G. bicolor and EDTA was $0.24 \mathrm{mg} / \mathrm{mL}$ and $0.03 \mathrm{mg} / \mathrm{mL}$, respectively. It was reported that metal ion chelating ability of polysaccharides may be due to the formation of cross-bridge between carboxyl group in uronic acid and divalent ion (Ge et al., 2014).

\section{Conclusions}

In summary, G. bicolor is an ideal source of antioxidant polysaccharides. A liquid-to-solid ratio of 30: $1(\mathrm{v} / \mathrm{w})$, a temperature of $80^{\circ} \mathrm{C}$ and an extraction time of $3 \mathrm{~h}$ were found to be optimal for antioxidant polysaccharide extraction from leaves of G. bicolor. The antioxidant abilities of G. bicolor polysaccharides mainly appeared as hydroxyl radical-scavenging activity as evidenced by $\mathrm{IC}_{50}$ of $4.67 \mathrm{mg} / \mathrm{mL}$. The results suggest that G. bicolor polysaccharides could be a promising source of natural antioxidant and be contributor to the health benefits of G. bicolor.

\section{Acknowledgements}

The authors gratefully acknowledge the financial supports by the Natural Science Foundation of Fujian Province, China (Grant No. 2012J05056), the Scientific Research Foundation for Returned Scholars, Ministry of Education of China (Grant No. LXKQ201301) and the National Natural Science Foundation of China (No.31201287).

\section{References}

Aruoma, O. I. (1998). Free radicals oxidative stress, and antioxidants in human health and disease. Journal of the American Oil Chemists' Society, 75(2), 199-212. http://dx.doi.org/10.1007/s11746-9980032-9

Bai, Y. H., Feng, Y. Q., Mao, D. B., \& Xu, C. P. (2012). Optimization for betulin production from mycelial culture of Inonotus obliquus by orthogonal design and evaluation of its antioxidant activity. Journal of the Taiwan Institute of Chemical Engineers, 43(5), 663-669. http:// dx.doi.org/10.1016/j.jtice.2012.03.004

Chen, G. T., Ma, X. M., Liu, S. T., Liao, Y. L., \& Zhao, G. Q. (2012). Isolation, purification and antioxidant activities of polysaccharides from Grifola frondosa. Carbohydrate Polymers, 89(1), 61-66. PMid:24750604. http://dx.doi.org/10.1016/j.carbpol.2012.02.045

Chen, S., Chen, H., Tian, J., Wang, J., Wang, Y., \& Xing, L. (2014). Enzymolysis-ultrasonic assisted extraction, chemical characteristics and bioactivities of polysaccharides from corn silk. Carbohydrate Polymers, 101, 332-341. PMid:24299781. http://dx.doi.org/10.1016/j. carbpol.2013.09.046

Chung, Y. C., Chang, C. T., Chao, W. W., Lin, C. F., \& Chou, S. T. (2002). Antioxidative activity and safety of the 50 ethanolic extract from red bean fermented by Bacillus subtilis IMR-NK1. Journal of Agricultural and Food Chemistry, 50(8), 2454-2458. PMid:11929313. http://dx.doi.org/10.1021/jf011369q

Dinis, T. C., Maderia, V. M., \& Almeida, L. M. (1994). Action of phenolic derivatives (acetaminophen, salicylate, and 5-aminosalicylate) as inhibitors of membrane lipid peroxidation and as peroxyl radical scavengers. Archives of Biochemistry and Biophysics, 315(1), 161-169. PMid:7979394. http://dx.doi.org/10.1006/abbi.1994.1485

Ge, Q., Huang, J., Mao, J. W., Gong, J. Y., Zhou, Y. F., \& Huang, J. X. (2014). Optimization of total polysaccharide extraction from Herba Lophatheri using RSM and antioxidant activities. International Journal of Biological Macromolecules, 67, 37-42. PMid:24608027. http://dx.doi.org/10.1016/j.ijbiomac.2014.02.055

Gulcin, I., Oktay, M., Kirecci, E., \& Kufrevioglu, O. I. (2003). Screening of antioxidant and antimicrobial activities of anise (Pimpinella anisum L.) seed extracts. Food Chemistry, 83(3), 371-382. http:// dx.doi.org/10.1016/S0308-8146(03)00098-0

Halliwell, B., \& Gutteridge, J. M. C. (1989). Free radicals in biology and medicine. Oxford: Oxford University Press.

Hayashi, M., Iwashita, K., Katsube, N., Yamaki, K., \& Kobori, M. (2002). Kinjiso (Gynura bicolor) coloredextract induce apoptosis in HL60 leukemia cells. Japan Society of Nutrition and Food Science, 49(8), 519-526. http://dx.doi.org/10.3136/nskkk.49.519

Jia, X., Ding, C., Yuan, S., Zhang, Z., Chen, Y., Du, L., \& Yuan, M. (2014). Extraction, purification and characterization of polysaccharides 
from Hawk tea. Carbohydrate Polymers, 99, 319-324. PMid:24274513. http://dx.doi.org/10.1016/j.carbpol.2013.07.090

Kozarski, M., Klaus, A., Niksic, M., Vrvic, M. M., Todorovic, N., Jakovljevic, D., \& Griensven, L. V. (2012). Antioxidative activities and chemical characterization of polysaccharide extracts from the widely used mushrooms Ganoderma applanatum, Ganoderma lucidum, Lentinus edodes and Trametes versicolor. Journal of Food Composition and Analysis, 26(1-2): 144-153. http://dx.doi. org/10.1016/j.jfca.2012.02.004

Mamani Chambi, H. N., \& Ferreira Grosso, C. R. (2011). Mechanical and water vapor permeability properties of biodegradables films based on methylcellulose, glucomannan, pectin and gelatin. Ciência e Tecnologia de Alimentos, 31(3), 739-746. http://dx.doi.org/10.1590/ S0101-20612011000300029

Martin, T. M., Yu, Y., Cui, Z. Q., \& Zhang, Y. (2012). Optimization and orthogonal design of an ultrasonic-assisted aqueous extraction process for extracting chlorogenic acid from dry tobacco leaves. Chinese Journal of Natural Medicines, 10(4), 311-320. http://dx.doi. org/10.3724/SP.J.1009.2012.00311

Masuko, T., Minami, A., Iwasaki, N., Majima, T., Nishimura, S., \& Lee, Y. C. (2005). Carbohydrate analysis by a phenol-sulfuric acid method in microplate format. Analytical Biochemistry, 339(1), 6972. PMid:15766712. http://dx.doi.org/10.1016/j.ab.2004.12.001

Nie, S. P., Cui, S. W., Xie, M. Y., Phillips, A. O., \& Phillips, G. O. (2013). Bioactive polysaccharides from Cordyceps sinensis: Isolation, structure features and bioactivities. Bioactive Carbohydrates and Dietary Fibre, 1(1), 38-52. http://dx.doi.org/10.1016/j. bcdf.2012.12.002

Nour, V., Trandafir, I., \& Cosmulescu, S. (2014). Antioxidant capacity, phenolic compounds and minerals content of blackcurrant (Ribes nigrum L.) leaves as influenced by harvesting date and extraction method. Industrial Crops and Products, 53, 133-139. http://dx.doi. org/10.1016/j.indcrop.2013.12.022

Qiao, D. L., Ke, C. L., Hua, B., Luo, J. G., Ye, H., Sun, Y, Yan, X. Y., \& Zeng, X. X. (2009). Antioxidant activities of polysaccharides from Hyriopsis cumingii. Carbohydrate Polymers, 78(2), 199-204. http:// dx.doi.org/10.1016/j.carbpol.2009.03.018

Sevag, M. G., Lackman, D. B., \& Smolens, J. (1938). The isolation of the components of streptococcal nucleoproteins in serologically active form. Journal of Biological Chemistry, 124(2), 425-436.

Shimizu, Y., Imada, T., Zhang, H., Tanaka, R., Ohno, T., \& Shimomura, K. (2000). Identification of novel poly-acylated anthocyanins from Gynura bicolor leaves. Food Science and Technology Research, 16(5), 479-486. http://dx.doi.org/10.3136/fstr.16.479

Tang, J., Nie, J., Li, D. P., Zhu, W. N., Zhang, S. P., Ma, F., Sun, Q., Song, J., Zheng, Y. L., \& Chen, P. (2014). Characterization and antioxidant activities of degraded polysaccharides from Poria cocos sclerotium. Carbohydrate Polymers, 105, 121-126. PMid:24708960. http://dx.doi. org/10.1016/j.carbpol.2014.01.049

Vissotto, L. C., Rodrigues, E., Chisté, R. C., Benassi, M. T., \& Mercadante, A. Z. (2013). Correlation, by multivariate statistical analysis, between the scavenging capacity against reactive oxygen species and the bioactive compounds from frozen fruit pulps. Ciência e Tecnologia de Alimentos, 33(supl. 1), 57-65. http://dx.doi. org/10.1590/S0101-20612013000500010

Wang, H. S., Wu, L., Cao, Y. M., \& Zang, L. Q. (2013). Hypoglycemic effects of Gynura bicolor on diabetes model rats. China Pharmacy, 11, 985-986.

Wang, Z., Wang, C., \& Quan, Y. (2014). Extraction of polysaccharides from Phellinus nigricans mycelia and their antioxidant activities in vitro. Carbohydrate Polymers, 99, 110-115. PMid:24274486. http:// dx.doi.org/10.1016/j.carbpol.2013.08.073 